\title{
EVANGÉLICOS SANGUESSUGAS, PRESIDENCIÁVEIS E CANDIDATOS GAÚCHOS: A DISPUTA PELO VOTO DOS GRUPOS RELIGIOSOS
}

\author{
Ricardo Mariano* \\ Marcio Hoff* \\ Toty Ypiranga de Souza Dantas ${ }^{* * *}$
}

Resumo: O paper analisa a disputa pelo voto de adeptos de grupos religiosos, em especial dos evangélicos, no primeiro turno das eleiçóes de 2006. Baseia-se em pesquisa empírica sobre o impacto do escândalo da máfia das sanguessugas na diminuição do tamanho da nova bancada evangélica no Congresso Nacional, a disputa dos candidatos à presidência da República pelo voto evangélico e a campanha eleitoral de candidatos que se identificaram como representantes dos cultos afro-brasileiros, dos católicos e das igrejas evangélicas nas eleições para o legislativo no Rio Grande do Sul.

Palavras-chave: evangélicos, católicos, afro-brasileiros, eleiçōes, Rio Grande do Sul.

O artigo se baseia numa investigação empírica sobre a participação dos evangélicos no primeiro turno das eleições de 2006. Destaca as eleições presidenciais, os efeitos do escândalo da máfia das sanguessugas na Frente Parlamentar Evangélica e a campanha eleitoral de candidatos evangélicos, católicos e afro-brasileiros a deputado estadual e federal no Rio Grande do Sul.

\section{OS EVANGÉLICOS E OS PRESIDENCIÁVEIS}

Em razão da expansão do pluralismo e da concorrência inter-religiosa, a tendência é que os diferentes grupos religiosos procurem dilatar seu poder político e sua ocupação dos espaços públicos, obedecendo ao lema corporativista “irmão vota em irmão" (Sylvestre, 1986). Para viabilizar e tornar mais eficiente sua missão conversionista num contexto secular e pluralista, tendem a adotar novas estratégias de ação em busca de vantagens competitivas,

* Doutor em Sociologia pela USP e coordenador do Programa de Pós-Graduação em Ciências Sociais da PUCRS.

** Mestrando em Ciências Sociais na PUCRS.

*** Graduando em Ciências Sociais na PUCRS e bolsista de iniciação científica do CNPq. 
além de reforçaro proselitismo, o ativismo do clero e dos leigos e a conquista de novos nichos de mercado. Para tanto, uma das estratégias consiste em adquirir meios de comunicação de massa e recursos públicos. No Brasil, a aquisição de ambos depende, em parte, da posse de poder político. Apesar de sua separação do Estado, a Igreja Católica continua sendo favorecida pelos poderes públicos e exercendo considerável influência política. Cientes disso, lideranças eclesiásticas e políticas evangélicas tentam ampliar seu poder e ativismo políticos para superar a concorrência católica e obter concessōes de emissoras de rádio e tevê, recursos públicos, legitimidade e respeitabilidade social, benefícios pessoais. Calculam que, quanto maiores forem seus poderesreligioso e político, maioresos benefícios públicos que conseguirão auferir. Daí a estratégia de envidar esforços para expandir sua ocupação religiosa do espaço público, sobretudo mediante a crescente inserção na política partidária, na mídia eletrônica e na área social. Por isso, desde o início dos anos 80 os pentecostais passaram a ingressar no campo político stricto sensu (Soares, 1983, 1985; Kliewer, 1982).

$\mathrm{O}$ ativismo político dos evangélicos, além disso, tem sido estimulado a cada processo eleitoral pela própria disputa de candidatos de todos os partidos para conquistar o voto do rebanho evangélico, sobretudo por meio da cooptação do apoio de suas lideranças eclesiásticas (Freston, 1993; Pierucci e Prandi, 1996). Fenômeno que se repetiu nas eleiçóes presidenciais de 2006, como se pode observar a seguir.

A campanha petista à presidência da República estabeleceu como uma de suas prioridades a conquista do voto evangélico. Com esse intento, Lula participou de reuniōes e eventos públicos com evangélicos, contou com comitês destinados a esse segmento religioso, pediu votos e oraçôes, prometeu criar um "canal direto" com a comunidade evan gélica ${ }^{1}$. Em carta enviada aos evangélicos, Lula prometeu ampliar as parcerias na área social do governo federal com as igrejas evangélicas. ${ }^{2}$ Num encontro com 30 cantores evangélicos, que for am ao Palácio Alvorada já no segu ndo turno pa ra manifes tar apoio à sua reeleição evento organizado pelo senador Marcello Crivella (PRB/RJ) -, o presidente candidato frisou: "Quis Deus que fosse esse, que era chamado de demônio, que fosse lá sancionar o Cód igo Civil que permite total liberdade de religião neste país" ${ }^{3}$ Segundo a propaganda do site do petista, seu governo "sancion ou a lei que garante a liberdade de culto no país", referindo-se à alteração do Cód igo Civil - medida proposta e d efend ida pela Fren te Parlamentar Evangélica - que mudou a personalidade jurídica das organizaçôes religiosas ${ }^{4}$. A sanção presidencial do Projeto de Lei 10.825, que alterou o Código Civil, foi acionada, desde o final de 2003, sistematicamente pelo petista para persuadir lideranças evangélicas sobre os benefícios que auferiram em seu primeiro mandato. Entre tais benefícios, reportagem da Folha de S. Paulo, de 18 de junho de 2006, revelou que o Governo Lula concedeu emissoras de rádio e tevê para igrejas e parlamentares evangélicos.

Para obter apoio da Universal já no primeiro turno e ampliar sua base eleitoral entre os evangélicos, Lula apoiou Marcelo Crivella (PRB/RJ) ao governo do Estado, deixando o can-

\footnotetext{
${ }^{1}$ Folha de S. Paulo, 18/8/2006.

${ }^{2}$ http://politica.dgabc.com.br/materia.asp?materia $=546212$

${ }^{3}$ Folha de S. Paulo, 10/10/2006.

${ }^{4}$ http://www.lulapresidente.org.br/noticia.php?codico=504
} 
didato petista, Vladimir Palmeira, à própria sorte. Tal como fizera no segundo turno da eleição presidencial de 2002, a Universal apoiou Lula, cujo vice, José Alencar, deixou o PL, antes dominado parcialmente pelo ex-bispo Carlos Rodrigues, para ingressar, por influência do Planalto, no PRB ${ }^{5}$, partido fundado e controlado por dirigentes da denominação. ${ }^{6}$ Registrado oficialmente em março de 2006, o PRB, ex-PMR, fez parte da coligação partidária do presidente, ao lado do PT e do PC do B. Essa aliança, cumpre frisar, é sintomática não só do pragmatismo eleitoral, mas também do quanto mudaram as lideranças petistas e da Universal e o quadro político brasileiro nos últimos anos. Haja vista que, na eleição presidencial de 1989, a Universal apoiou Collor e demonizou Lula o máximo que pôde (Mariano e Pierucci, 1992). Em 1994, repetiu a dose, satanizando o candidato petista e seu partido. Em 1998, optou pela neutralidade, não apoiando nenhum candidato a cargo majoritário. Em 2002, apoiou Garotinho no primeiro turno e o petista, no segundo. Em 2006, aliou-se a Lula logo no primeiro turno; apoio que consolidou forte guinada na estratégia e nas alianças políticas de sua cúpula eclesiástica, mudança favorecida pelo redirecionamento ideológico do PT rumo ao centro do espectro partidário, pelo assistencialismo do Governo Lula e por seu conservadorismo na condução da política monetária.

De olho no voto evangélico, o Palácio do Planalto fez de tudo para afastar o précandidato Anthony Garotinho do páreo. Apesar de vencer as prévias do PMDB em meados de 2006, Ga rotinho - que no primeiro turno de 2002 obteve 51\% do total de votos dos evangélicos (Boh n, 2004) - não con seguiu demover os dirigentes governistas de seu partido, insuflados pelo Planalto, da decisão de abrir mão da candidatura própria para apoiar a reeleição de Lula. Sem a opção Garotinho, a preferida pelas principais lideranças da Assembléia de Deus e de outras igrejas evangélicas, o apoio desses religiosos se dividiu entre os candidatos do PT e do PSDB, predominando a preferência pelo petista.

Fora do páreo e ressentido, Garotinho, identificando-se como professor da escola bíblica da "Igreja Presbiteriana na classe dedicada aos casais", passou a atacar o candidato petista, visando desqualificá-lo junto ao eleitorado evangélico. Além de desferir ataques ao PT e aos auxiliares do presidente envolvidos em casos de corrupção, empregou acusações tidas como eficazes nesse meio religioso. O curioso foi observá-lo, justamente quem há pelo menos uma década não mede esforços para transformar o rebanho evangélico num reba nho eleitoral, acusar, in dignado, o petis ta de usar "a fé das pessoas para ganhar votos". Em seu site, escreveu:

“...é inadmissível que um cristão renomado, que conheça a palavra de Deus, vote em Lula, sabendo o que ele faz para ganhar voto. Você se lembra de Lula tomando banho de pipoca na Bahia, atrás dos votos dos umbandistas? Você se lembra de Lula participando de uma sessão de vodu, segundo ele para fechar o corpo e afastar os maus espíritos, em recente viagem à África? (...) Respeito a religião de cada um, mas é inadmissível que

${ }^{5}$ Caçula, o PRB foi o partido com menor número de candidatos, 103 no total: um a governador, um a senador, 28 a deputado federal, 70 a estadual, três a distrital, cf. Folha de S. Paulo, 4/8/2006.

${ }^{6}$ Gazeta Mercantil, 3/10/2005. 
alguém conhecedor da palavra de Deus vote num presidente que faz política com religião usando a fé das pessoas para ganhar votos"?

Não obstante diversas resistências à candidatura de Lula nesse meio religioso, sua ofensiva sobre o eleitorado evangélico surtiu efeito. Em 8 de setembro, a Convenção Nacional das Assembléias de Deus (CONAMAD), dirigida por Manuel Ferreira, que apoiara José Serra no segundo turno das eleições presidenciais de 2002, manifestou apoio oficial à reeleição do presidente, em reunião com cerca de mil pastores em templo da Assembléia de Deus no Rio de Janeiro. A cerimônia contou com a presença de Lula, que não só se apresentou como "homem defé", como enfatizou, tal como fez efaria outras vezes, referin do-se à alteração do Código Civil: "Quis Deus que eu fosse eleito presidente e criasse uma lei estabelecendo defin itivamente a liberdade religiosa”. Ajustando o discurso a seu públicoalvo, arrematou: "Somos todos crentes, brasileiros e amamos este país". ${ }^{8}$ Enquanto isso, integrantes do Conselho Político da Convenção Geral das Assembléias de Deus (CGADB) cogitavam retirar o apoio a Geraldo Alckmin, em razão do fraco desempenho do candidato do PSDB nas pesquisas, apoio que se confirmou posteriormente.

A comparação de resultados de pesquisa do Datafolha de setembro de 2002 e julho de 2006 revela que o percentual de evangélicos com intenção de votar no petista no primeiro turno cresceu $59 \%$ no período?. Essa expansão, porém, verificou-se apenas no segmento pentecostal. A intenção de voto em Lula saltou de $27 \%$ para $43 \%$ entre os pentecostais, mas declinou de $41 \%$ para $34 \%$ entre os evangélicos históricos. Após o início do horário eleitoral, o percentual de pentecostais que votaria em Lula no primeiro turno subiu de $43 \%$ para $52 \%{ }^{10}$. Mais pobres e menos escolarizados, os pentecostais seguiram, em parte, a tendência eleitoral dominante nesses estratos sociais. Mais escolarizados e com renda mais elevada, os evangélicos históricos acompanharam, parcialmente, a tendência eleitoral rival, ampliando seu apoio ao candidato do PSDB à presidência.

O Movimento Evangélico Progressista (MEP), que, nas eleições presidenciais anteriores, apoiou o candidato petista, decidiu, em congresso nacional realizado em Guarulhos, "não declarar apoio a nenhum candidato no primeiro turno", considerando haver vários candidatos no "campo progressista". Apesar disso, militantes deSão Paulo incluíram "o MEP em alguns documentos de apoio a Lula", atitude que foi reprovada por membros da diretoria nacional. Seu secretário executivo, Geter Borges, em comunicado aos membros e diretores do MEP, sugeriu que a entidade não se posicionasse a favor de Lula no segundo turno, por con ta dos "casos de cor rupção envolvendo o PT e as semelhanças dos programas" dos candidatos petista e tucano. Nessa sugestão, por certo, pesou também a divisão das preferências no seio do movimento, majoritariamente de classe média, por ambos os candidatos.

${ }^{7}$ http://www.anthonygarotinho.com.br/?tc=17\&id=3512

${ }^{8}$ Folha de S. Paulo, 9/9/2006.

${ }^{9}$ Folha de S. Paulo, 18/8/2006.

${ }^{10} \mathrm{http}: / /$ www.valo ronl ine. com. br/valore cono mico/285/pri meirocad erno/politica/Orfaos + de+ Garotinho+evangelicos+dividem-se+entre+Lula+e+Alckmin,,,60,3891265.html 
As campanhas de Alckmin, à presidência, e de Serra, ao governo do Estado de São Paulo, formaram igualmente um núcleo responsável para conquistar apoio evangélico. Entre outras investidas eleitorais nesse meio religioso, os candidatos assistiram a um culto da Assembléia de Deus, do Bom Retiro. Identificado com grupos católicos conservadores, entre os quais a Opus Dei, Alckmin recebeu apoio da liderança da Comunidade Paz e Vida durante culto reunindo cerca de dois mil fiéis e participou da festa de aniversário do líder da Comunidade da Graça. Faltando menos de duas semanas antes do primeiro turno, no dia 18 de setembro, o tucano obteve, depois de longa espera, o apoio oficial da cúpula da Convenção Geral das Assembléias de Deus no Brasil, ramo assembleiano majoritário no país. Com baixa penetração eleitoral entre os mais pobres, justamente o extrato social predominante no pentecostalismo, o tucano obteve baixa adesão de pentecostais à sua candidatura: somente $25 \%$ em pesquisa do Datafolha realizada em julho. Além disso, somente $19 \%$ do eleitorado brasileiro identificaram-no como candidato que "mais defenderá os pobres" (contra 48\% para o petista), e 32\% associaram-no à defesa dos ricos. ${ }^{11}$

\section{DE SAL DA TERRA E LUZ DO MUNDO ÀS SANGUESSUGAS: A RESSACA MORAL DOS EVANGÉLICOS}

A denúncia de envolvimento de diversos deputados evangélicos no escândalo da máfia das sanguessugas teve por efeito imediato diminuir drasticamente o tamanho da bancada evangélica no Congresso Nacional no último pleito. Haja vista que nenhum dos deputados evangélicos denunciados conseguiu ser reeleger. Dos 60 membros da Frente Parlamentar Evangélica, somente 15 deputados federais foram reeleitos. A bancada evangélica minguou, em razão da queda acentuada do número de eleitos da Assembléia de Deus e da Universal do Reino de Deus, justamente as igrejas cujos políticos foram mais diretamente afetados pelas denúncias de superfaturamento e distribuição de propinas na compra de ambulâncias. Como atesta o DIAP: "Depois do primeiro teste das urnas em 2006, a bancada evangélica foi a que mais diminuiu entre os grupos de pressão organizados que atuam no Congresso." 12

Tudo fazia crer que a bancada evangélica continuaria ampliando pouco a pouco seu tamanho, até a hecatombe das sanguessugas, que feriu de morte o elevado orgulho moral desse grupo religioso minoritário em solo nacional. Esperava-se a manutenção da tendência de expansão da base parlamentar evangélica, tendo em vista o retrospecto político recente desse grupo religioso, que, em menos de 20 anos, duplicara o número de parlamentares, como segue. Em 1986, os evangélicos elegeram 32 parlamentares para o Congresso Nacional. Em 1990, foram 23 deputados federais, queda de nove.Em 1994,30, sendo 26 deputados e 4 senadores. Em 1998, 49 parlamentares. Em 2002, alcançou 59 deputados federais e

${ }^{11}$ Folha de S. Paulo, 10/9/2006.

12 http://www.diap.org.br/eleicoes/2006.asp?codigo1=8944\#8944 
quatro senadores. Em 2003, formou-se a Frente Parlamentar Evangélica, composta por 60 parlamentares de mais de uma dezena de partidos e de igrejas, compondo a terceira maior bancada do Congresso Nacional. Em 2006, porém, veio a derrocada. Identificamos 40 deputados federais evangélicos eleitos, conforme a Tabela 1, para a legislatura de 2007 a 2010. Além dos quatro senadores eleitos em 2002, deve haver mais um ou outro parlamentar evangélico, chegando a uma cifra um terço menor, portanto, que a da bancada anterior. Vamos ao escândalo responsável por tamanha queda na representação política evangélica.

Em 3 de maio de 2006, a Polícia Federal iniciou a Operação Sanguessuga, com base em levantamento da Controladoria Geral da União, que identificou irregularidades e superfaturamento na compra de ambulâncias em diversas prefeituras, com verba do Fundo Nacional de Saúde. O esquema de corrupção envolvia funcionários do Ministério da Saúde, prefeitos, deputados federais, senadores, assessores parlamentares e a empresa Planam. Seu proprietário, Luiz Antônio Trevisan Vedoin, propôs a parlamentares a elaboraçáo de emendas ao orçamento para liberar recursos para que prefeituras comprassem ambulâncias, ônibus e equipamentos médicos, vendidos superfaturados por sua empresa. Aprovadas as emendas, a Planam orientava a elaboração dos editais de licitação, monitorava seu trâmite e redigia os documentos de compra e venda dos equipamentos. Em troca, agraciava os demais membros da "máfia" com presentes e propinas entre $10 \%$ e $15 \%$ do valor das emendas. ${ }^{13}$

As resistências de lideranças políticas governistas não conseguiram superar a pressão da opinião pública e a disposição dos partidos de oposição para criar a CPMI das Sanguessugas, em 14 de junho. Pouco depois, no início de julho, foi divulgada a lista de 72 parlamentares envolvidos no esquema, entre os quais constavam 28 evangélicos. Cifra que representa a metade da bancada evangélica eleita em 2002, composta por 59 deputados e quatro senadores. Em 10 de agosto, a CPMI aprovou relatório recomendando a abertura de processo de cassação de 27 parlamentares evangélicos. ${ }^{14}$

Em depoimento à Justiça Federal e à CPMI, Vedoin afirmou que a bancada evangélica participou ativamente do esquema, arrecadando cerca de $\mathrm{R} \$ 53$ milhões, dos quais $\mathrm{R} \$$ 9 milhôes gastos com o direcionamento de emendas. ${ }^{15}$

Dos 22 deputados federais da Assembléia de Deus, 10 foram acusados de participar da "máfia” das sanguessugas: Adelor Vieira (PMDB/SC), Agnaldo Muniz (PP/RO), Cabo Júlio (PMDB/MG), Carlos Nader (PL/RJ), Gilberto Nascimento ${ }^{16}$ (PMDB/SP), Isaías Silvestre (PSB/MG), Neuton Lima (PTB/SP), Nilton Capixaba (PTB/RO), Pastor Amarildo (PSC/

${ }^{13}$ http://www.diariodaserra.inf.br/showpolitica.asp? codigo $=99952$

${ }^{14}$ Segue a lista dos cassáveis: Adelor Vieira, Agnaldo Muniz, Almeida de Jesus, Almir Moura, Cabo Júlio, Carlos Nader, Edna Macedo, Heleno Silva, Isaías Silvestre, João Batista, João Mendes de Jesus, Jorge Pinheiro, José Divino, Josué Bengtson, Lino Rossi, Magno Malta, Marcos Abramo, Marcos de Jesus, Neuton Lima, Nilton Capixaba, Pastor Amarildo, Paulo Baltazar, Paulo Gouvêa, Raimundo Santos, Reginaldo Germano, Vieira Reis, Wanderval Santos.

15 http://www1.folha.uol.com.br/folha/brasil/ult96u81306.shtml

${ }^{16}$ Gilberto Nascimento, Jefferson Campos e Zelinda Novaes foram absolvidos pelo relatório parcial da CPI, mas tiveram pedido de abertura de inquérito aceito pelo STF e serão investigados pelo Ministério Público Federal. 
TO), Raimundo Santos (PL/PA). Seguem abaixo denúncias contra alguns deles. O líder da Frente Parlamentar Evangélica, Adelor Vieira (PMDB/SC), em troca de R\$ 26 mil em dinheiro e R $\$ 14$ mil em serviços prestados por gráficas de Joinville, teria apresentado emenda orçamentária de R \$ 560 mil em favor da Sociedade de Assistência Social e Educacional Deus Proverá (Sasedesp), ligada a sua igreja. ${ }^{17}$ Em sua defesa, entregou à CPMI carta da Sasedesp negando seu envolvimento no processo licitatório, além de duas correspondências de gráficas prestadoras de serviço ao parlamentar alegando não ter recebido dinheiro da Planam. Fracassou na tentativa de reeleição, apesar de receber o apoio da igreja. ${ }^{18}$ Obteve apenas 47.341 votos. ${ }^{19}$ Já o deputado assembleiano Agnaldo Muniz (PP/RO), líder do PP em Rondônia, foi acusado de receber R $\$ 10$ mil em dinheiro na conta do "laranja" Floripes Santos. O deputado afirmou, em nota, desconhecer o teor das acusações e se disse vítima de calúnia. ${ }^{20}$ Responsável por sua escolha como candidato oficial da igreja para a Câmara Federal, pastor Nélson Luchtemberg, seu sogro e líder da Assembléia de Deus em Rondônia, acusou os denunciantes de "satanis tas desocupados". ${ }^{21}$ Denunciado como chefe do esquema em Minas Gerais, Cabo Júlio (PMDB/MG) teria recebido 14 pagamentos em sua conta bancária, somando R \$ 83 mil. Em troca, elaborou emendas e organizou encontros de prefeitos mineiros com a Planam, em sua chácara. ${ }^{22}$ Investigado pela Procuradoria-Geral da República, desistiu de concorrer à reeleição ${ }^{23}$. Nilton Capixaba (PTB/RO), segundo-secretário da Câmara, teve a mensalidade da escola particular dos filhos paga pela Planam, segundo Darci Vedoin.

Deputados de outras igrejas foram acusados também pela CPMI. Da Internacional da Graça de Deus, o deputado Almir Moura (PFL/RJ), e da Evangelho Quadrangular, os deputados Jefferson Campos (PTB/SP) e Josué Bengtson (PTB/PA). Dos batistas, apenas dois foram acusados de participar da máfia das sanguessugas. Lino Rossi teria sido responsável por apresentar a Vedoin boa parte dos parlamentares evangélicos que se integraram à "máfia". ${ }^{24}$ Outro batista envolvido foi o senador Magno Malta (PL/ES). Segundo o relator de seu processo, senador Demóstenes Torres (PFL/GO), Lino Rossi teria oferecido um Fiat Ducato, pago por Vedoin, a Magno Malta, que usou o veículo em viagens de sua banda gospel, Tempero do Mundo. ${ }^{25}$ Malta alegou não ter apresentado emendas para a compra de ambulâncias, descumprindo sua parte no trato com Vedoin.

A Universal foi a igreja mais gravemente atingida pelo escândalo das sanguessugas. 14 de seus 16 deputados federais foram denunciados: Almeida de Jesus (PL/CE), Bispo Vieira Reis (sem partido/RJ), Bispo Wanderval (PL/SP), Edna Macedo (PTB/SP), João

\footnotetext{
${ }^{17}$ htt p://n ews.tce.sc.gov.br/Apl ic/ clipping. nsf/\$default view/F4521 E22 FC47FD4C 832571 B2003EAE64?

${ }^{18} \mathrm{http} / / /$ portal.an.uol.com.br/2006ago/11/0des.jsp

${ }^{19} \mathrm{http}: / /$ www.tre-sc.gov.br

${ }^{20}$ http://www.tudorondonia.com.br/new/ler.asp?id=393

${ }^{21} \mathrm{http}: / /$ www.tudorondonia.com.br/new/ler.asp?id=555

${ }^{22} \mathrm{http} / / / \mathrm{www} \cdot$ rondonoticias.com.br/showNew.jsp?CdMateria=53370\&CdTpMateria=7

$23 \mathrm{http}: / /$ opiniaoenoticia.com.br/interna.php? $\mathrm{mat}=4787$

${ }^{24}$ http://www1.folha.uol.com.br/folha/brasil/ult96u82619.shtml

${ }^{25}$ http://www.agenciabrasil.gov.br/noticias/2006/09/20/materia.2006-09-20.8176192213/view
} 
Batista (PP/SP), João Mendes de Jesus (sem partido/RJ), Pastor Heleno (PL/SE), Jorge Pinheiro (PL/DF), José Divino (sem partido/RJ), Marcos Abramo (PP/SP), Marcos de Jesus (sem partido/PE), Paulo Gouvêa (PL/RS), Reginaldo Germano (PP/BA), Zelinda Novaes (PFL/BA). Além deles, Carlos Rodrigues (PL/RJ), ex-deputado e ex-coordenador político da igreja, foi preso pela Polícia Federal em 5 de maio, no início da Operação Sanguessuga. ${ }^{26}$ Edna Macedo (PTB/SP), irmã do bispo Macedo, foi acusada de receber R\$ 40 mil, dos quais R\$30 mil em dinheiro para si e o restante na conta de seu filho Otávio José Bezerra Sampaio, que foi preso junto com Rodrigues. ${ }^{27}$

Para minimizar os danos à reputação da denominação, já tão maculada nas duas últimas décadas, sua cúpula eclesiástica retirou o apoio eleitoral aos deputados denunciados. Sem apoio institucional e, portanto, sem viabilidade eleitoral, a maioria desistiu da candidatura. Dos acusados, apenas dois tentaram a reeleição, sem sucesso: Paulo Gouvêa (PL/RS) e João Mendes de Jesus (PSB/RJ). Edna Macedo (PTB/SP) renunciou ao mandato para escapar da cassação. Em seguida, candidatou-se à deputada estadual, mas teve a candidatura suspensa pelo Superior Tribunal de Justiça Eleitoral, que não contabilizou seus votos à espera de parecer do Ministério Público. ${ }^{28}$

A Universal teve uma ascensão política meteórica. Em 1986, com apenas nove anos de existência, elegeu um deputado federal. Em 1990, foram três. Quatro anos depois, seis. Em 1998, 17 deputados federais, sendo 14 da própria igreja. Nesse período, a expansão de sua base parlamentar foi concomitante com a ampliação de seu domínio do PL e com a liderança, pelo então Bispo Rodrigues, da bancada evangélica no Congresso Nacional. Em 2002, elegeu 16 deputados federais e um senador (Oro, 2003, p. 53-54). Em 2006, sob o impacto do caso das sanguessugas, recuou para 5 deputados federais, apenas um terço de sua bancada anterior. Frente à acentuada ascensão dos últimos pleitos, o resultado foi pífio, ainda mais por ocasião da criação do PRB, tendo em suas fileiras o vice-presidente da República e um prestigiado filósofo de Harvard.

A Assembléia de Deus perdeu quase a metade de sua bancada no Congresso, declinando de 22 para 12 deputados. Ao contrário da Universal, que afastou os parlamentares envolvidos no escândalo, a cúpula eclesiástica e política da denominação adotou, conforme as idiossincrasias de cada liderança estadual, uma atitude mais ou menos ambígua, enquanto noutros manteve o apoio aos denunciados. A igreja reuniu os acusados e instaurou sindicância interna para apurar os fatos. Para Ronaldo Fonseca, pastor presidente do Conselho Polític o da CGADB, sete dos denun ciados da igreja são “inocentes”. Segundo reportagem do Congresso em Foco, para líderes da Assembléia de Deus, o caso das sanguessugas é uma “'jogada política” para reduzir a bancada evangélica e, com isso, facilitar a aprovação de projetos polêmicos, como a discriminalização do aborto". ${ }^{29}$

\footnotetext{
${ }^{26}$ Afastado em fevereiro de 2004 da Universal, Carlos Rodrigues (PL/RJ) foi acusado de participar no "mensaláo" e no caso "Valdo miro", relacionado à CPI dos Bingos. Renunciou ao mandato de deputado federal para evitar a cassação.

${ }^{27}$ http://canais.ondarpc.com.br/noticias/brasil/conteudo.phtml?id=562104

${ }^{28} \mathrm{http}: / /$ www.tre-sp.gov.br

${ }^{29} \mathrm{http}: / /$ www.congressoemfoco.com.br/Noticia.aspx?id=10539
} 
A ênfase na posse de uma ética superior, biblicamente fundamentada, foi sempre poderosa bandeira eleitoral brandida por candidatos evangélicos para legitimar, em seu meio religioso, sua inserção na política partidária e tentar conquistar o voto de seus irmãos de fé. Até porque, segundo Ari Pedro Oro (2001, 61), os evangélicos "se consideram uma espécie de 'reserva moral da sociedade”". Em seu próprio jargão, julgam-se "sal e luz da ter ra”. Sal, para, mediante uma conduta exemplar, purificar os impuros; luz, subentendendo a posse do monopólio da verdade divina, para iluminar os ímpios nos caminhos do Senhor rumo à retidão moral e à salvação celestial. Esse forte orgulho moral foi, em parte, ladeira abaixo com a irrupção das sanguessugas evangélicas. Terminou em ressaca moral. Outros escândalos já atingiram políticos evangélicos, como os ocorridos na Constituinte e na CPI dos Anões do Orçamento, mas nenhum dos anteriores foi tão abrangente, impactante e vexaminoso como o atual..$^{30}$ Pelo dissabor, pela frustração e pela revolta causados no eleitorado evangélico, era esperada a vingança dos irmãos nas urnas. Foi o que aconteceu.

Tabela 1. Deputados Federais evangélicos eleitos para 2007-2010 31

\begin{tabular}{|c|c|c|}
\hline Deputados & Partido & Igreja \\
\hline Antônio Cruz & $\mathrm{PP} / \mathrm{MS}$ & Assembléia de Deus \\
\hline Dr. Nechar & $\mathrm{PV} / \mathrm{SP}$ & Assembléia de Deus \\
\hline Filipe Rio de Cara Nova & $\mathrm{PSC} / \mathrm{RJ}$ & Assembléia de Deus \\
\hline Francisco Rossi & $\mathrm{PMDB} / \mathrm{SP}$ & Assembléia de Deus \\
\hline João Campos & $\mathrm{PSDB} / \mathrm{GO}$ & Assembléia de Deus \\
\hline João Oliveira & $\mathrm{PFL} / \mathrm{TO}$ & Assembléia de Deus \\
\hline Jurandyr Loureiro & $\mathrm{PSC} / \mathrm{ES}$ & Assembléia de Deus \\
\hline Pastor Manuel Ferreira & $\mathrm{PTB} / \mathrm{RJ}$ & Assembléia de Deus \\
\hline Sandro Matos & $\mathrm{PTB} / \mathrm{RJ}$ & Assembléia de Deus \\
\hline Silas Câmara & $\mathrm{PTB} / \mathrm{AM}$ & Assembléia de Deus \\
\hline Takayama & $\mathrm{PMDB} / \mathrm{PR}$ & Assembléia de Deus \\
\hline Zequinha Marinho & $\mathrm{PSC} / \mathrm{PA}$ & Assembléia de Deus \\
\hline Arolde de Oliveira & $\mathrm{PFL} / \mathrm{RJ}$ & Batista \\
\hline Edinho Montemor & $\mathrm{PSB} / \mathrm{SP}$ & Batista \\
\hline Gilmar Machado & $\mathrm{PT} / \mathrm{MG}$ & Batista \\
\hline Leonardo Quintão & $\mathrm{PMDB} / \mathrm{MG}$ & Batista \\
\hline Lincoln Portela & $\mathrm{PL} / \mathrm{MG}$ & Batista Renovada \\
\hline Natan Donadon & $\mathrm{PMDB} / \mathrm{RO}$ & Batista \\
\hline Neucimar Fraga & $\mathrm{PL} / \mathrm{ES}$ & Batista \\
\hline
\end{tabular}

${ }^{30}$ Sobre a voracidade fisiológica de políticos evangélicos na Constituinte, ver Pierucci (1989).

${ }^{31}$ A lista é parcial, fruto de coletas em sites do DIAP e do Congresso em Foco, entre outros, além de informe do MEP.

Debates do NER, Porto Alegre, ANo 7, n. 10, P. 65-78, jul./Dez. 2006 


\begin{tabular}{|c|c|c|}
\hline Sérgio Brito & PDT/BA & Batista \\
\hline Sueli Vidigal & PDT/ES & Batista \\
\hline Walter Pinheiro & PT/BA & Batista \\
\hline Julio Redecker & PSDB/RS & Luterana \\
\hline Luiz Carlos Heinze & PP/RS & Luterana \\
\hline Onyx Lorenzoni & PFL/RS & Luterana \\
\hline Bispo Antônio Bulhões & PMDB/SP & IURD \\
\hline Flávio Bezerra & PMDB/CE & IURD \\
\hline George Hilton & PP/MG & IURD \\
\hline Léo Vivas & PRB/RJ & IURD \\
\hline Paulo Roberto & PTB/RS & IURD \\
\hline Andréia Zito & PSDB/RJ & Maranata \\
\hline Carlos Manato & PDT/ES & Maranata \\
\hline Carlos Willian & PST/MG & Maranata \\
\hline Bispo Rodovalho & PFL/DF & Sara Nossa Terra \\
\hline Eduardo Cunha & PMDB/RJ & Sara Nossa Terra \\
\hline Mário de Oliveira & PSC/MG & Quadrangular \\
\hline Dona Íris Rezende & PMDB/GO & Cristã Evangélica \\
\hline Henrique Afonso & PT/AC & Presbiteriana \\
\hline Adílson Soares & PL/RJ & Internacional da Graça \\
\hline Marcos Antônio 32 & PSC/PE & Metodista Wesleyana \\
\hline
\end{tabular}

\section{OS CANDIDATOS EVANGÉLICOS, CATÓLICOS E AFROS NO RIO GRANDE DO SUL}

A pesquisa investigou também a campanha de fiéis religiosos e pastores, presbíteros, obreiros, padres, sacerdotes e pais-de-santo para deputado estadual e federal no Rio Grande do Sul nas eleiçóes de 2006. Ao todo, identificamos 40 candidatos a deputado estadual que publicizaram seus vínculos religiosos durante a campanha para angariar votos, num universo de 490 que concorreram às 55 cadeiras da Assembléia Legislativa gaúcha. Para a Câmara Federal, identificamos 24 candidatos religiosos entre os 279 que disputaram o pleito no Estado. Para identificá-los, consultamos homepages do Tribunal Superior Eleitoral, dos partidos políticos e de alguns grupos religiosos, contatamos funcionários de partidos políticos, participamos de eventos e cultos religiosos, acompanhamos a propaganda eleitoral no rádio e na tevê, realizamos entrevistas semi-diretivas. Apesar disso, vários candidatos provavelmente não foram identificados. A lista é parcial, mas representativa. Como nos

${ }^{32}$ Há dúvida sobre a denominação de Marcos Antônio. Para alguns, ele é da Assembléia de Deus.

Debates do NER, Porto Alegre, ANo 7, N. 10, P. 65-78, JUl./DEZ. 2006 
pleitos anteriores, predominaram as candidaturas de evangélicos, seguidas, em menor número, por uma minoria católica e afro-brasileira. A maioria dos candidatos foi contatada por telefone e 11 - residentes em Cachoeira do Sul, Canoas, Charqueadas, Camaquã, Carazinho, Sapucaia do Sul, Porto Alegre e Santa Maria - entrevistados pessoalmente antes de findar o primeiro turno.

A pesquisa procurou traçar as trajetórias religiosa e política dos candidatos gaúchos, observar suas propostas e o engajamento ou não de lideranças eclesiásticas em sua campanha eleitoral. Aqui, faremos uma apresentação sumária dos dados. Dos 64 candidatos que disputaram uma vaga para deputado estadual e federal, nove tentaram a reeleição, apenas três com êxito. Boa parte dos demais candidatos participou do processo eleitoral pela primeira vez, sem ter experiência política prévia. Atualmente, dez candidatos exercem mandato de vereador em municípios do Rio Grande do Sul. Deles, um é católico, João Carlos Nedel (PP), os demais, evangélicos. ${ }^{33}$ Nada menos que 37 deles exercem cargos religiosos: são 28 pastores, três evangelistas, dois bispos evangélicos, um padre e um pai-de-santo.

Concorrendo com 12 candidatos a deputado estadual e 10 a federal, a Assembléia de Deus não realizou convenção para definir candidatos oficiais, visando estimular novos pastores e membros a concorrer. Sem concentrar a votação do rebanho nos candidatos oficiais, não conseguiu eleger representante algum. O fracasso atingiu até Edemar Vargas (PTB/RS), apesar de seus três mandatos consecutivos na Assembléia Legislativa. O insucesso não se deveu somente à fragmentação dos votos em seus candidatos, mas também à indiferença e, provavelmente, até ao boicote de parte do eleitorado assembleiano, em reação ao protagonismo de políticos da denominação na máfia das sanguessugas. Com isso, o total de votos obtidos pelos 12 candidatos da Assembléia de Deus a deputado estadual (53.934) foi inferior à votação do deputado oficial da Universal, Carlos Gomes (66.454). Fenômeno que se repetiu para deputado federal: os 10 candidatos da Assembléia de Deus obtiveram 81.711 votos, enquanto Paulo Roberto, sozinho, alcançou 84.123 votos. No Rio Grande do Sul, após retirar o apoio eleitoral de Paulo Gouvêa e afastá-lo da igreja, a Universal conseguiu conter a sangria e emplacar seus candidatos oficiais.

Desrespeitando a nova legislação eleitoral, a Universal realizou campanha eleitoral em seus cultos em Porto Alegre e demais municípios do estado, divulgando o nome dos "candidatos de Deus" em detrimento dos que identificou com o "mal", o "demônio". A Universal teve dois candidatos oficiais: bispo Paulo Roberto (PTB), para deputado federal, e pastor Carlos Gomes (PPS), para estadual. Ambos foram os únicos evangélicos eleitos no Rio Grande do Sul em 2006, ao lado dos luteranos reeleitos Onyx Lorenzoni (PFL), Júlio Redecker (PSDB) e Luiz Carlos Heinze (PP), nenhum com apoio das denominações luteranas. Outros cinco se identificaram como pertencentes à Universal, incluindo o deputado federal Paulo Gouvêa, acusado de sanguessuga, mas nenhum deles recebeu seu apoio. Pastor Sérgio Pérez, atual deputado estadual da igreja, registrou sua candidatura no TSE, mas fez campanha para Carlos Gomes, recebendo apenas 22 votos.

${ }^{33}$ A Assembléia Legislativa do Rio Grande do Sul publicou, em dezembro de 2005, a revista Sondagem dos Vereadores: quem são os vereadores do Rio Grande do Sul?, na qual revelou que 11,9\% dos vereadores gaúchos são evangélicos.

Debates do NER, Porto Alegre, ANo 7, n. 10, P. 65-78, jul./Dez. 2006 
O Conselho Estadual de Diretores da Evangelho Quadrangular realizou uma prévia interna com pastores e bispos, 12 meses antes das eleiçôes, e decidiu apoiar oficialmente dois de seus cinco candidatos: Uberani Barbosa, para deputado estadual, e Reinaldo Santos, tentando a reeleição, para federal, ambos pelo PTB. ${ }^{34}$ Os candidatos não-oficiais concorreram mesmo sem o apoio da denominação. Apesar do apoio oficial, Uberani e Reinaldo não lograram êxito, tal como os demais.

A Internacional da Graça de Deus teve um candidato oficial, Adelar Ivan Bayer (PTB), e outros quatro que se lançaram por conta própria, sem sucesso. Os cinco somaram apenas 9.209 votos. A Evangélica Pentecostal Cristã teve dois, mas só apoiou um, Bispo Volmar dos Santos (PSDB). Brasil para Cristo, Sara Nossa Terra, Manancial da Graça, Presbiteriana do Brasil, Universal do Reino de Cristo e Adventista do Sétimo Dia tiveram um candidato cada. As batistas contaram com sete candidatos.

Como era de se esperar, na campanha, os candidatos evangélicos efetuaram diversas propostas moralistas e corporativistas, que prometiam advogar em seus mandatos, como: defender a união da família, dos princípios cristãos e da liberdade religiosa; auxiliar servidores federais e entidades religiosas; criar mecanismos para frear as leis de liberação do aborto de casamento civil de pessoas do mesmo sexo; angariar recursos para desenvolver projetos sociais das igrejas; adquirir ônibus com palco e sonorização para evangelismo; defender a construção de templos religiosos sem atender às especificações da lei do Estatuto das Cidades; fazer reconhecer que as igrejas fazem parte da sociedade. As causas mais restritamente moralistas e corporativistas são as únicas capazes de unir os políticos evangélicos como uma bancada, ou frente parlamentar. De partidos e igrejas diversos e concorrentes, sua atuação parlamentar, na maioria das votações, costuma obedecer às pressóes e escolhas partidárias (Fonseca, 2002). Priorizar propostas moralistas e corporativistas na campanha, além disso, visa atender a interesses específicos de sua base eleitoral. Daí seu uso freqüente e estratégico nas campanhas.

Adversários dos evangélicos, os cultos afro-brasileiros foram representados por dois candidatos a deputado estadual: Toni de Exu (PTB) e Edson Portilho (PT). Num de seus santinhos, Toni de Exú Rei se proclamou "o único candidato para defender a religião africana, a umban da e a exub an da" das "mentiras e difamaçôes" da Igreja Universal no Rio Grande do Sul, classificando o grupo religioso adversário de "máquina eletrônica de lavar dinheiro à custa da fé d o povo". Preterido pelos grupos afros, obteve apenas 1.731 votos.

O principal candidato dos afros foi o petista Edson Portilho, que concorreu à reeleição. No atual mandato, Portilho sobressaiu-se como defensor dos cultos afro-brasileiros gaúchos, sendo decisivo na luta contra a lei que instituiu o Código Estadual de Proteção aos Animais, de autoria do pastor da Quadrangular e deputado Manuel Maria (PTB). O Código, segundo material de propaganda eleitoral do candidato, constituía "um instrumentolegal para proibir os africanis tas de exercerem livremente seus rituais religiosos", ou para "al guns setores intolerantes" "perseguir os batuqueiros". A mobilização dos grupos afros, que, entre outras ações, reuniram cerca de mil pessoas na Assembléia Legislativa em julho de 2003, e de Portilho, como seu representante político, garantiram a aprovação da Lei 12.131, de 22 de julho de

${ }^{34}$ Jornal Zero Hora, 6/8/2006. "Venha a nós o vosso voto". 
2004, que acrescentou parágrafo único ao artigo $2^{\circ}$ da Lei 11.915 , excetuando, nas proibições estabelecidas pelo Código Estadual de Proteção aos Animais, o sacrifício ritual efetuado pelas religiões de matriz africana. Embora tenha recebido o apoio majoritário de lideranças de entidades afro-brasileiras e do movimento negro, Portilho não foi reeleito, o que comprova mais uma vez a debilidade político-eleitoral dos cultos afros.

A Igreja Católica, por determinação oficial, não apóia candidatos políticos. A cada eleição, porém, a CNBB edita cartilha para orientar os fiéis, oferecendo "critérios de discern imento" e de "escolha dos can didatos" e orientações para a ação "à luz de princípios éticos e cristãos". ${ }^{35} \mathrm{Na}$ s "or ienta çōes" de 2006, en fatiza a ét ica, as lutas por justiça social, a proteção da vida e do meio ambiente, a ampliação da participação popular nos debates e políticas públicos, a democratização do Estado, o combate à corrupção e às políticas de cunho neoliberal.

No Rio Grande do Sul, um padre, Sadi Cordeiro (PV), e três leigos, Paulo Savaris (PMDB), para estadual, Juliano Paz (PSB) e João Carlos Nedel (PP), para federal, disputaram as eleições, empregando os termos "católico" e "católico pratican te" em seus santinhos. Nenhum deles foi eleito. Nedel, vereador de Porto Alegre e ministro da eucaristia, destacou-se por seu apetite e empenho para tentar cativar o eleitorado católico, apelando para a defesa da moral, de valores e de princípios cristãos tradicionais. No material de campanha, invocou a reação da maioria católica para eleger cristãos contra a corrupção e a imoralidade, pontificando: "Nós, católicos, somos $80 \%$ do eleitorado brasileiro. É preciso acordar essa maioria silenciosa. Grande parte desse contingente continua votando em candidatos anticristãos, os quais defendem o aborto, a eutanásia, a liberação das drogas e o casamento homossexual. Tudo contrário aos princípios da Igreja”. Sua ladainha conservadora, sua vereança na capital e sua campanha na seara católica, contudo, não foram suficientes para elegê-lo. Obteve 16.720 votos.

Mesmo destino teve o candidato a deputado estadual Ademir de Souza (PL), que se identificou como membro da seicho-no-iê, de origem oriental. Proporcional ao tamanho diminuto de seu grupo religioso no estado e no Brasil, sua votaçáo alcançou apenas 925 votos.

Como se pôde observar, o uso da identificação religiosa foi uma constante na campanha de dezenas de candidatos evangélicos, afro-brasileiros e católicos ao legislativo no Rio Grande do Sul. E suas estratégias foram as mais diversas. Em relação ao principal grupo religioso investigado nesse trabalho, excetuando os casos em que houve apoio denominacional oficial, como nas igrejas Quadrangular e Universal, por exemplo, os candidatos evangélicos freqüentemente tentaram obter o apoio de lideranças eclesiásticas. Sua predileção por essa estratégia leva em conta a forte influência pastoral sobre o rebanho de fiéis, que, como revela Simone Bohn (2004), tem baixa exposição aos meios de comunicação e à imprensa escrita, mas, em compensação, constitui uma clientela muito exposta à autoridade dos dirigentes eclesiásticos, por sua elevada freqüência semanal aos cultos e atividades religiosas. Autoridade pastoral que se transmuta mais facilmente em autoridade política no caso da orientação eleitoral para votar nas candidaturas de irmãos da igreja, mas

35 O documento da CNBB de 2006 está no site http://wwww.adital.com.br/site/ noticia.asp?lang=PT\&cod $=22858$

Debates do NER, Porto Alegre, ANo 7, n. 10, P. 65-78, jul./Dez. 2006 
que não tem o mesmo efeito para os candidatos não evangélicos a cargos legislativos e majoritários. Apesar disso, os candidatos a cargos majoritários não abrem mão desse apoio, como bem demonstram a campanha e a corrida de Lula e Alckmin às igrejas evangélicas. Com isso, tende a se ampliar, não obstante o desastroso tropeço dos evangélicos nestas eleições, a ocupação do espaço e dos poderes públicos por grupos e políticos religiosos.

\section{REFERÊNCIAS}

BOHN, Simone R. Evangélicos no Brasil. Perfil socioeconômico, afinidades ideológicas e determinantes do comportamento eleitoral. Opinião Pública, vol. 10, n. 2, Campinas, out. 2004. FONSECA, Alexandre Brasil. Secularização, pluralismo religioso e democracia no Brasil: um estudo sobre a participação dos principais atores evangélicos na política. São Paulo, Tese de Doutorado em sociologia, FFLCH-USP, 2002.

FRESTON, Paul.Protestantes e política no Brasil: da Constituinte ao impeachment. Campinas, Tese de Doutorado em sociologia, IFCH-Unicamp, 1993.

KLIEWER, G. U. Assembléia de Deus e eleições num município do interior do Mato Grosso. Rio de Janeiro, Comunicações do ISER, n. 3, 1982.

MARIANO, Ricardo, PIERUCCI, Antônio Flávio. O envolvimento dos pentecostais na eleição de Collor. Novos Estudos Cebrap, n. 34, 1992, p. 92-106.

ORO, Ari Pedro. Religião e Política nas eleiçōes 2000 em Porto Alegre. Debates do NER, Porto Alegre, UFRGS, ano 2, n. 3, 2001.

. Religiōes e eleiçōes em Porto Alegre: um comparativo entre 2000 e 2004. Debates

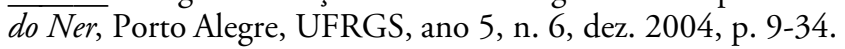

A política da Igreja Universal e seus reflexos nos campos religioso e político brasileiros. Revista Brasileira de Ciências Sociais, v. 18, n. 53, out. 2003.

PIERUCCI, Antônio Flávio. Representantes de Deus em Brasília: a bancada evangélica na Constituinte. Ciências Sociais Hoje, 1989. São Paulo: Vértice / Revista dos Tribunais, ANPOCS, 1989, p. 104-132.

PIERUCCI, Antônio Flávio, PRANDI, Reginaldo. A realidade social das religiōes no Brasil: religião, sociedade e política. São Paulo: Hucitec, 1996.

SOARES, Mariza. Em debate: a política como caminho da salvação. Rio de Janeiro: Comunicações do ISER, n. 6, 1983, p. 10-21.

. Os crentes nas eleições. Religião e Sociedade, ISER/CER, 12/3, 1985.

SYLVESTRE, Josué. Irmão vota em irmão. Os evangélicos, a Constituintee a Bíblia. Brasilia: Pergaminho, 1986. 